\title{
NLCs as a potential carrier system for transdermal delivery of forskolin*
}

\author{
Elwira Lasoń1 ${ }^{\llbracket}$, Elżbieta Sikora1, Małgorzata Miastkowska, Elvira Escribano², Maria Jose Gar- \\ cia-Celma², Conxita Solans ${ }^{3}$, Meritxell Llinas ${ }^{3}$ and Jan Ogonowski ${ }^{1}$
}

1Faculty of Chemical Engineering and Technology, Institute of Organic Chemistry and Technology, Cracow University of Technology, Kraków, Poland; 2Department of of Pharmacy and Pharmaceutical Technology and Physical-Chemistry, Faculty of Pharmacy and Food Sciences, University of Barcelona, Joan XXIII s/n, E-08028 Barcelona, Spain. IN UB members; ${ }^{3}$ nnstitute for Advanced Chemistry of Catalonia, Consejo Superior de Investigaciones Científicas (IQAC-CSIC) Centro de Investigación Biomédica en Red en Bioingeniería, Biomateriales y Nanomedicina (CIBER-BBN) Barcelona, Spain

\begin{abstract}
Nanostructured lipid carriers (NLC) composed of the substances generally recognized as safe (GRAS) were obtained by using a hot high-pressure homogenization technique (HPH). The influence of the number of homogenization cycles and concentration of a decyl glucoside surfactant on the NLC properties were studied. The system's stability was assessed by macroscopic observation, light backscattering and zeta potential measurements. NLC particle size was measured using dynamic light scattering (DLS). The kinetically stable formulations were loaded with forskolin and selected for in vitro drug permeation study using the Franz cell method. Concentration of forskolin in the receptor solution (i.e. ethanol/ PBS mixture) was analyzed with high performance liquid chromatography (HPLC) with UV detection. The obtained results have shown that NLC formulations could be used as effective carriers for forskolin permeation through the skin.
\end{abstract}

Key words: Forskolin, NLC, nanostructured lipid carrier, skin permeation

Received: 19 January, 2018; revised: 04 April, 2018; accepted: 26 July, 2018; available on-line: 15 September, 2018

$\triangle$ e-mail: elason@chemia.pk.edu.pl

*Preliminary report presented at 6th Central European Congress of Life Sciences. EUROBIOTECH, 11-14 September, 2017. Kraków, Poland

Abbreviations: NLC, nanostructured lipid carrier; SLN, solid lipid nanoparticle; HPH, high pressure homogenization

\section{INTRODUCTION}

Nanostructured lipid carriers (NLCs) one of the main types of lipid nanoparticles, are alternative carrier systems next to emulsions, liposomes and polymeric nanocapsules. And as a second generation of lipid nanoparticles they have many advantages over solid lipid nanoparticles (SLN). NLCs are produced using blends of solid and liquid lipids (oils) in contrast to SLNs, which contain only solid lipids. A certain amount of oil in NLCs leads to a less perfect crystal structure, which contributes to an increased active loading capacity and minimizes, or even prevents, the expulsion of drug during storage (Müller et al., 2002a; Zheng et al., 2013).

Therefore, lipid nanoparticle formulations with solid matrix have shown great potential as carriers for topical administration of poorly soluble active ingredients. Over the past few years they have been studied intensively for dermal applications, for both pharmaceutical and cosmetic applications (Müller et al., 1995; Müller et al., 2002a; Pardeike et al., 2009; Müller et al., 2007). They have many advantages important for this kind of products, e.g. they increase skin hydration and occlusive properties (Wissing \& Müller, 2003) enable the modified release profile (Jenning et al., 2000; Souto et al., 2004) increase skin penetration related to a targeting effect and avoidance of systemic absorption (Liu et al., 2007; Chen et al., 2006). Moreover, lipid nanoparticles enhance the stability of chemically labile drugs and active ingredients (Souto \& Müller, 2005; Üner et al., 2005; Junyapraserta et al., 2009).

Recent research has indicated that nanoparticular systems, such as lipid nanoparticles (SLNs, NLCs) show improved uptake and skin targeting (Gelfuso et al., 2016). Nanoparticles like liposomes (De Leeuw et al., 2009) oilbased dispersions (Konan et al., 2002) polymeric particles (Gomes et al., 2007) or gold nanoparticles (Cheng et al., 2008) have been successfully applied to create a new drug delivery system for treatment of skin cancer. The main focus has been put on diagnosing and treating metastatic melanoma, which is the deadliest skin cancer (Vyas et al., 2012). Many chemotherapeutics administrated systematically are cytotoxic to healthy cells, therefore nanomedicine aims to design nanoparticles which could selectively deliver drug specifically to the melanoma cells (Chen et al., 2010; Dhar et al., 2011).

Forskolin is a diterpene produced by the Indian Coleus plant (Coleus forskoblii) and an interesting active compound showing potential to protect skin from the UVB damage. It activates adenylyl cyclase and therefore increases the intracellular levels of cAMP (cyclic adenosine monophosphate) (Burlando et al., 2010). It has been demonstrated that inducing pigmentation with forskolin provides effective protection against UVB-induced DNA damage and skin cancer in mice deficient for a DNA repair enzyme. Passeron and others (Passeron et al., 2009) demonstrated in their study that forskolin protects keratinocytes from UVB induced apoptosis independently of the amount of melanin in the skin. They proved that it enhances the removal of cyclobutane pyrimidine dimers and 6,4-photoproducts, which are the two major types of UVB-induced DNA damage, and facilitates DNA repair. These results imply new preventive approaches with topical formulations containing forskolin, which could be applied to the skin before sun exposure. Moreover, forskolin has appeared in the literature as a natural substance to obtain a healthy $\tan$ (Spry et al., 2009).

The objective of this study was to develop and optimize stable NLC formulations based on mixture of 
beeswax and caprylic/capric triglycerides as the carriers for topical administration of forskolin, which could be potentially used as an alternative drug carrier.

\section{MATERIALS AND METHODS}

Materials. In this study we used the following solid lipids: Apifil ${ }^{\circledR}$ (PEG-8 beeswax; Gattefossé GmbH, Weil am Rhein, Germany) Cutina ${ }^{\circledR} \mathrm{CP}$ (cetyl palmitate, BASF Chem Trade GmbH, Burgbenheim, Germany) Compritol $^{\circledR} 888$ ATO (glyceryl behenate, Gattefossé $\mathrm{GmbH}$, Weil am Rhein, Germany) Carnauba wax (Kahlwax, Kahl GmbH \& Co. KG, Trittau, Germany). Labrafac ${ }^{\circledR} \mathrm{CC}$ (caprylic/capric triglycerides, Gattefossé $\mathrm{GmbH}$, Weil am Rhein, Germany) and Cetiol ${ }^{\mathbb{}} \mathrm{V}$ (decyl oleate, BASF Chem Trade GmbH, Burgbenheim, Germany) were liquid lipid used. PlantaCare ${ }^{\mathbb{R}}$ 2000UP (decyl glucoside, BASF Chem Trade GmbH, Burgbenheim, Germany) was applied as a surfactant. An active substance, Forslean (Coleus Forskoblii Root Extract containing $95 \%$ of forskolin) was purchased from Sabinsa Europe $\mathrm{GmbH}$, Langen, Germany). The ultra-purified water was freshly prepared by a MiliQ ${ }^{\circledR}$ System (Millipore, Schwalbach, Germany).

Forskolin solubility. Prior to the NLCs production a lipid screening was performed to determine the most suitable lipids with respect to the solubility of forskolin to be incorporated. This was done by heating the solid lipid, $5^{\circ} \mathrm{C}$ above its melting point, and dissolving an increasing amount of forskolin therein. After dissolution, the mixture of lipids and the active ingredient was cooled down to room temperature for solidification and then visually examined for the presence of crystalline forskolin. Additionally, to exclude presence of forskolin crystals in the lipid matrix, we used Leica Reichert Polyvar 2 microscope with a hot plate and a polarizer.

Preparation of NLC. Free and forskolin-loaded NLCs were prepared using hot high-pressure homogenization method (HPH). A certain amount of solid lipid $\left(\right.$ Apifil $\left.{ }^{\circledR}\right)$ and liquid oil $\left(\right.$ Labrafac $\left.^{\circledR} \mathrm{CC}\right)$ were melted in various solid to liquid lipid ratios (Table 1) at $80^{\circ} \mathrm{C}$, to get a uniform oil phase. When needed, forskolin was added to the oil phase. Next, the melted lipid phase was dispersed in the hot surfactant water solution by using high speed magnetic stirrer (Agimatic-N, P Selecta) at $750 \mathrm{rpm}$, for $5 \mathrm{~min}$. The obtained pre-emulsion was subsequently homogenized at $75^{\circ} \mathrm{C}$, using the high-pressure homogenizer (Microfluidics Corporation, Newton Massachusetts) at 275 bar. The number of homogenization cycles ranged from 3 to 6 . For a comparative study, a nanoemulsion was prepared, using Labrafac ${ }^{\circledR} \mathrm{CC}$ as an oil phase, and production parameters that were the same as for NLCs with 3 homogenization cycles.

Zeta potential analysis. Zeta potential (ZP) of NLC dispersions was determined by the measurement of the electrophoretic mobility, using Malvern 4700C Sub Micron Particle Analyzer. The conversion into the ZP was performed using Helmholtz-Smoluchowski equation. ZP was measured at room temperature after dilution of samples with deionized water. The measurements for each sample were repeated three times.

Particle size measurements. Mean particle size of the lipid dispersions (z-ave) and the polydispersity index (PI) which is a measure of the width of the size distribution, were determined using Dynamic Light Scattering (DLS) method, using Malvern 4700C Sub Micron Particle Analyzer. Analyses were performed using a $90^{\circ}$ scattering angle at $25^{\circ} \mathrm{C}$. Prior to the measurements, all samples were diluted with deionized water to have a suitable scattering intensity. During the experiment, refractive index of the samples was set at 1.450 . For each sample the analysis was performed three times to determine mean values.

NLC stability studies. The stability of NLC formulations was firstly evaluated by macroscopic observation and estimating the "cream" increasement in time by measuring the height of delamination. The samples of equal volume were observed daily over three weeks, and any destabilization processes (creaming or coalescence) were measured.

After macroscopic observation, the stability of the most stable NLC formulations was additionally assessed by light backscattering, by means of a Turbiscan Lab ${ }^{\circledR}$ Expert (Formulation SA, France) at constant temperature $\left(32^{\circ} \mathrm{C}\right)$. Transmission and backscattering data were acquired for $24 \mathrm{~h}$, in intervals of 2 hour, according to the method proposed by Caldero and others (Caldero et al., 2011).

In vitro skin permeation studies. For the skin permeation study, human skin samples obtained by abdominoplasty surgeries were kindly provided by Clínica Sagrada Familia, Barcelona, Spain. Before each experiment, skin integrity was evaluated by measuring the transepidermal water loss (TEWL) of skin pieces. In vitro permeation through human epidermis $(0.4 \mathrm{~mm})$ from the same donor was assessed using the MicroettePlusR system (Hanson Research, USA). The experiments were performed at $32^{\circ} \mathrm{C} \pm 0.5,400 \mathrm{rpm}$, using mixture of PBS

Table 1. The NLC systems' composition and obtaining parameters.

\begin{tabular}{|c|c|c|c|c|}
\hline \multirow{2}{*}{ Formulation name } & \multicolumn{3}{|c|}{ Ingredients (\%wt.) } & \multirow{2}{*}{ Number of homogenization cycles } \\
\hline & oil & solid lipid & surfactant & \\
\hline NLC-3 & 3 & 7 & 2 & \multirow{6}{*}{3} \\
\hline $\mathrm{NLC}-4$ & 3 & 7 & 4 & \\
\hline NLC-5 & 4.5 & 10.5 & 2 & \\
\hline NLC-6 & 6 & 14 & 2 & \\
\hline NLC-7 & 4.5 & 10.5 & 4 & \\
\hline NLC-8 & \multirow{4}{*}{6} & \multirow{4}{*}{14} & \multirow{4}{*}{4} & \\
\hline NLC-9 & & & & 4 \\
\hline NLC-10 & & & & 5 \\
\hline NLC-11 & & & & 6 \\
\hline
\end{tabular}

*water up to $100 \%$ wt., 270 bar, $75^{\circ} \mathrm{C}$ 


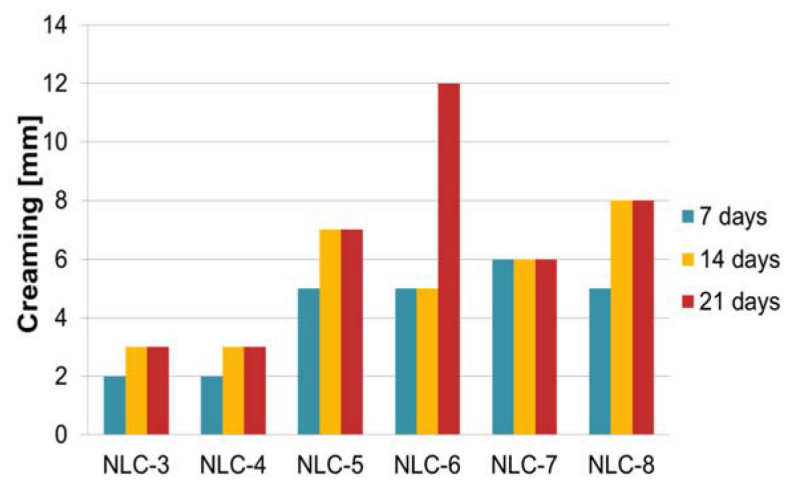

Figure 1. Effect of NLC's composition on creaming phenomena ( 3 cycles, $\mathrm{p}=275 \mathrm{bar}, \mathrm{T}=75^{\circ} \mathrm{C}$ ).

( $\mathrm{pH}$ 7.4)/ethanol $(60: 40, \mathrm{~V} / \mathrm{V})$ as receptor solution (sink conditions). An adequate amount of formulation $(0.350 \mathrm{ml})$ was placed in the donor part at Franz diffusion cells. Samples of $700 \mu \mathrm{l}$ were withdrawn automatically from the receptor compartment. The acceptor fluid was collected subsequently during $24 \mathrm{~h}$. The number of replicates per formulation was $n=6$.

Estimated permeation parameters were: flux at steady state $\left(J_{s s}\right)$ by means of a linear regression (cumulative permeated amount vs. time, slope) lag time (TL) (X-intercept) permeability coefficient $\left(K_{\mathrm{p}}=J_{\mathrm{ss}} / C_{\text {formulation }}\right)$ partition parameter $P_{1}$ and the apparent length of diffusion parameter $P_{2}$ (according to: Okamoto (Okamoto et al., 1986) and Selzer (Selzer et al., 2013). The steady state flux through the membrane is given by: $J_{\mathrm{ss}}=C_{0} \cdot K_{\mathrm{p}}=C_{0} \cdot(\mathrm{K} \cdot$ $D) / L$, where $C_{0}$ is the constant forskolin concentration in the donor compartment, $K$ is the partition coefficient vehicle/skin, $D$ is the diffusion coefficient of the permeant in the skin and $L$ is the effective diffusion path length. Since $L$ is unknown, the expression $(K \cdot D) / L$ can be replaced by the product of $P_{1}$ and $P_{2}$ parameters, being $P_{1}=K \cdot L$ and $P_{2}=D / L^{2}$; the calculation of $P_{2}$ is obtained from $1 / 6 \cdot \stackrel{2}{T}_{\mathrm{I}}$.

The parameters calculated were compared by a non-parametric statistical assay (Kruskall-Wallis Z) $(p<0.05)$ according to Williams and others (Williams et al., 1992) and followed by Kruskal-Wallis Multiple-Comparison Z-Value Test.

HPLC analysis. Concentration of the active ingredient in acceptor medium of the permeation assays was analyzed using HPLC Waters instrument, operated at room temperature, consisting of an automatic auto sampler system, equipped with UV detector and Spherisorb ODS column $(5 \mathrm{~mm} \times 15 \mathrm{~cm} \times 0.46 \mathrm{~cm})$. The mobile phase was isocratic ( 60 volumes of acetonitrile and 40 volumes of water) which remained constant throughout the entire analysis. The flow rate was set to $0.5 \mathrm{ml} /$ min. The assay was monitored at the wavelength of 210 $\mathrm{nm}$, sample injection volume was $20 \mu \mathrm{l}$ and run time 10 min. The active ingredient's content was identified by comparing its retention time and UV spectra. The calibration curve was constructed from linear plots of peak area versus concentration.

\section{RESULTS AND DISCUSSION}

\section{Forskolin solubility in lipids}

A precondition for a successful encapsulation of forskolin into NLC system is its applicable solubili-
Table 2. Solubility of forskolin in solid and liquid lipids.

\begin{tabular}{|c|c|}
\hline Lipids & max solubility, $\mathrm{mg} / \mathrm{mL}$ \\
\hline Apifil ${ }^{\circledR}$ & 3.2 \\
\hline Cutina $\mathrm{CP}^{\oplus}$ & n.d. \\
\hline Compritol $^{\circledast} 888$ ATO & 1.3 \\
\hline Canauba wax & n.d. \\
\hline Labrafac $^{\circledast}$ CC & 3.5 \\
\hline Cetiol V & 1.5 \\
\hline Apifil $^{\otimes} /$ Cetiol V & 1.3 \\
\hline Apifil $^{\otimes} /$ Labrafac $^{\oplus}$ CC & 6.2 \\
\hline Compritol $^{\circledR} 888$ ATO / Labrafac ${ }^{\oplus}$ CC & 1.2 \\
\hline Compritol $^{\circledR} 888$ ATO / Cetiol V & 1.2 \\
\hline Cutina $\mathrm{CP} \otimes /$ Labrafac $^{\oplus} \mathrm{CC}$ & n.d. \\
\hline
\end{tabular}

*Ratio of solid to liquid lipid ratio was 70/30; n.d., not analyzed amount

ty in the lipid. Therefore, the four chosen solid lipids (Apifil ${ }^{\circledR}$, Cutina ${ }^{\circledR} \mathrm{CP}$, Compritol ${ }^{\mathbb{}} 888$ ATO, Carnauba wax) and their mixture with liquid lipids (Labrafac ${ }^{\circledR} \mathrm{CC}$, Cetiol ${ }^{\mathbb{V}} \mathrm{V}$ ) in the ratio $70: 30$ were screened. The obtained results showed that the best solvent for forskolin was Apifil ${ }^{\circledR} /$ Labrafac ${ }^{\circledR} C C$ mixture (Table 2). It was further chosen to produce forskolin-loaded NLCs.

\section{NLC stability}

The high-pressure homogenization technique, using a varying number of process cycles was applied for NLCs preparation. Moreover, influence of lipids' concentration, solid to liquid lipids ratio, and concentration of surfactant on NLCs' stability were studied.

Figure 1 shows the results of creaming phenomena for formulations with different composition, obtained by $\mathrm{HPH}$ method ( 3 cycles, $p=275$ bar, $T=75^{\circ} \mathrm{C}$ ). It has been found that increase in the solid lipid content in formulation: 7, 10.5, and 14\% for NLC-3, NLC5 , and NLC-6, respectively, resulted in a creaming increasement.

NLC formulations were prepared applying a varying number of homogenization cycles (3, 4, 5, or 6). Figure 2 shows the influence of the number of homogenization cycles on NLCs' stability (composition of the formulations, pressure and temperature of homogenization were maintained constant). The obtained results show that creaming with 3 homogenization cycles and

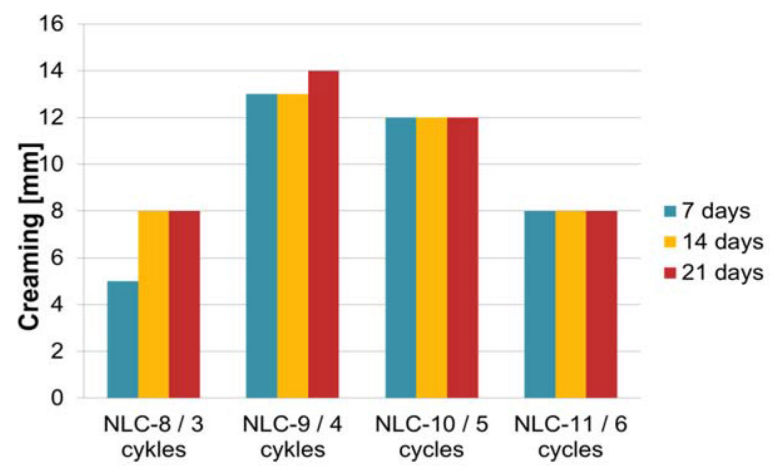

Figure 2. Influence of the number of homogenization cycles on creaming phenomena. 


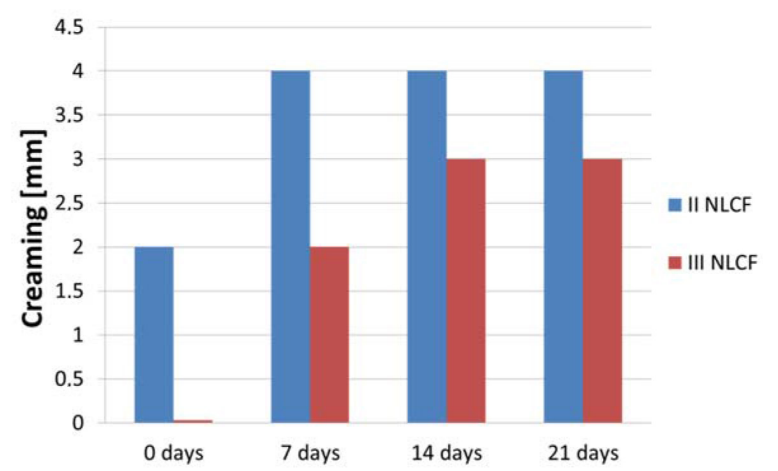

Figure 3. Influence of surfactant concentration on creaming phenomena (II NLCF, $2 \%$ of surfactant; III NLCF, $4 \%$ of surfactant).

6 homogenization cycles were similar. Taking into consideration the economy and efficiency of the homogenization process, 3 cycles of the microfluidizer setting were finally chosen to obtain forskolin loaded NLC.

The choice of surfactant and its concentration has an impact on the quality of NLC dispersion (Mulla \& Khazi, 2009). In our work decyl glucoside (PlantaCare ${ }^{\circledR 2000 U P)}$ was chosen as an emulsifier because of its dermatologically compatible properties and unpreserved form, which is very important in skin care products. A sufficient amount of a surfactant must be used to cover the newly formed surfaces, created during high-pressure homogenization process. The influence of the surfactant content on creaming phenomena in the formulations of the same lipid concentration is presented in Fig. 3. Increasing the surfactant content from $2 \%$ to $4 \%$ wt. resulted in an increase of the systems stability. The concentration above $4 \%$ wt. was not considered, as it was observed that higher concentration of PlantaCare ${ }^{\circledR} 2000$ UP caused foam formation during the high-pressure homogenization process.

Zeta potential ( $\mathrm{ZP})$ is often a key factor used to evaluate the stability of colloidal dispersion. Particle aggregation is less likely to occur for charged particles with high zeta potential (more than $|30| \mathrm{mV}$ ) because of electric repulsion. Generally, lipid nanoparticles (SLNs, NLCs) are negatively charged on the surface (Schwarz \& Menhert, 1999). In our formulations all the zeta potential values were less then $-30 \mathrm{mV}$; nevertheless, destabilization processes in form of creaming were observed in many cases. Non-ionic surfactant, like alkyl polyglucoside, cannot ionize into charging group like the ionic surfactants, but indicates its ZP. It might be because of molecular polarization and adsorption of surfactant molecule on the charge in water, it was absorbed to the emulsifier layer of particle/water interface, and an electric double layer similar to ionic was formed (Han et al., 2008).

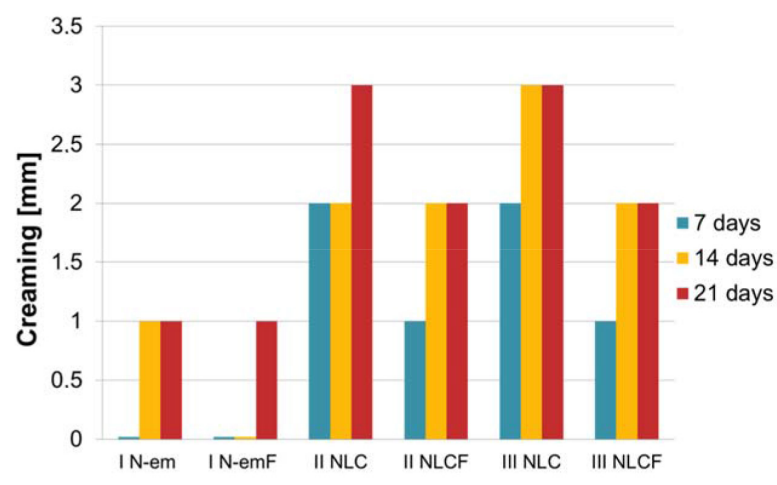

Figure 4. Influence of forskolin on creaming phenomena I N-em, nanoemulsion; I N-emF, forskolin-loaded nanoemulsion; II NLC formulation with $2 \%$ wt. of surfactant; II NLCF, forskolinloaded formulation with $2 \%$ wt. of surfactant; III NLC formulation with $4 \%$ wt. of surfactant; III NLCF, forskolin-loaded formulation with $4 \%$ wt. of surfactant.

\section{Characterization of forskolin-loaded NLC}

Considering the results obtained in the first part of our study, we chose the optimal formulation for the active ingredient incorporation. NLCs that contained $0.075 \%$ wt. of forskolin, 3\% wt. of Labrafac ${ }^{\circledR}$ CC, $7 \%$ wt. of Apifil ${ }^{\circledR}$ and $2 \%$ (II NLCF) or $4 \%$ wt. (III NLCF) of PlantaCare ${ }^{\circledR} 2000$ UP were prepared and characterized. Moreover, a nanoemulsion (I N-emF) with this same percentage of oil/surfactant was also prepared for comparison (Table 3).

During stability study of forskolin-loaded NLCs it was confirmed (Fig. 3) that 4\% wt. content of surfactant in the formulations (III NLCF) is sufficient to obtain a stable system. It was also found that addition of forskolin positively affected the stability of NLC systems. Figure 4 shows the effect of forskolin presence in the formulations (II NLCF, III NLCF) compared to formulations without the active ingredient (II NLC, III NLC) on the process of creaming. It can be clearly seen, that NLCs containing forskolin (II NLCF, III NLCF) do not show the further creaming process after 7, 14 and 21 days, contrary to formulations without the active ingredient.

Additionally, the stability analysis of the pre-selected for in vitro skin permeation study formulation (III NLCF) and the nanoemulsion prepared for a comparison (I $\mathrm{N}$-emF) were also assessed using Turbiscan $\mathrm{Lab}^{\circledR} \mathrm{Ex}-$ pert. This method is non-destructive, as no dilution of the sample is necessary, and gives the information on the kind of destabilization process. Turbiscan measurements are based on the variation of the droplet volume fraction (creaming/sedimentation) or mean size (coalescence) which result in the variation of backscattering and transmission signals (Paolino et al., 2011). These signals occur as a function of time (and particle migration) and

Table 3. The optimal formulations for drug encapsulation.

\begin{tabular}{|c|c|c|c|c|c|c|c|}
\hline \multirow{2}{*}{ Formulation name } & \multicolumn{4}{|c|}{ Ingredients (\% wt.) } & \multirow{2}{*}{$\mathrm{ZP}[\mathrm{mV}]$} & \multirow{2}{*}{ Z-ave $[\mathrm{nm}] \pm$ S.D. } & \multirow{2}{*}{ PDI } \\
\hline & Oil & Solid lipid & Surfactant & Forskolin & & & \\
\hline I N-emF & 10 & - & 2 & 0.075 & -44.2 & $168.5 \pm 6.6$ & 0.211 \\
\hline II NLCF & 3 & 7 & 2 & 0.075 & -32.3 & $174.8 \pm 5.3$ & 0.315 \\
\hline III NLCF & 3 & 7 & 4 & 0.075 & -36.5 & $184.4 \pm 3.8$ & 0.309 \\
\hline
\end{tabular}

*water up to $100 \%$ wt. 


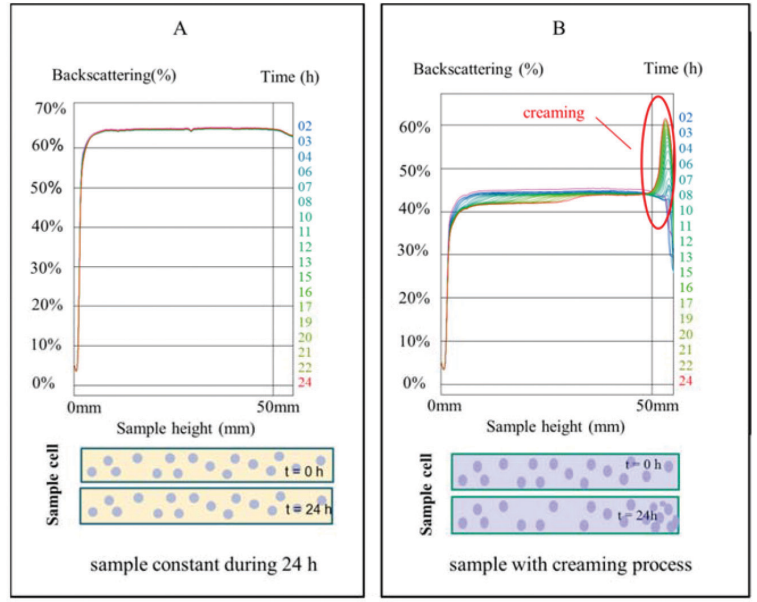

Figure 5. Comparison of backscattering data of (A) nanoemulsion (I N-emF) and (B) III NLCF

are graphically reported in the form of positive (backscattering increase) or negative peaks (backscattering decrease). No variations of particle size take place when the backscattering profile is within the interval $\pm 2 \%$. Variations greater than $10 \%$ represent destabilization which will occur over time (Fig. 5).

\section{In vitro skin permeation}

The skin permeation of forskolin contained in the NLC system (III NLCF) nanoemulsion (I N-emF) and Labrafac ${ }^{\mathbb{B}} \mathrm{CC}$ was studied. The results of the in vitro percutaneous permeation experiments are presented in Fig. 6 and Table 4. As it can be observed, the highest permeation through the skin profile of forskolin was achieved in Labrafac $\mathrm{CC}^{\circledR}(p<0.05)$ and could be mainly attributed to a higher skin/vehicle partition coefficient (reflected in the value of the parameter $P_{1}$ ) that could favor the active ingredient's penetration through the stratum corneum. The percentage of forskolin permeated at $24 \mathrm{~h}$ was very high (near $80 \%$ ).

Both assayed nanoformulations showed similar permeation profiles. According to the permeation parameters (Table 4) the calculated $\mathrm{Kp}$ enhancement ratio of IN-emF with respect to IIINLCF is close to 1 (1.12). This shows that the permeability coefficients were very similar, which would be in accordance with the high lipophilicity of forskolin and the lipophilic nature of the stratum corneum. However, the permeation was slightly higher in case of the emulsion. This higher permeation could be explained by a higher thermodynamic activity of forskolin in the oil of the nanoemulsion (Labrafac

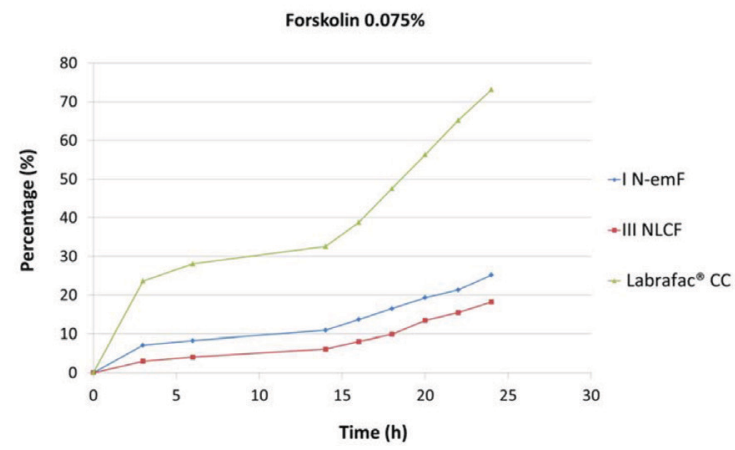

Figure 6. Mean skin permeation profile of forskolin in nanoemulsion (I N-emF) NLC (III NLCF) and oil (Labrafac CC ${ }^{\circ}$ ).

$\mathrm{CC}^{\circledR}$ ) with respect to the mixture Apifil/Labrafac $\mathrm{CC}^{\circledR}$ of the NLC, according to its solubility in the oil phases (Table 2). Thermodynamic activity is the main driving force for skin permeation (Kemken, 1991) and it would lead to fast diffusion of forskolin through the skin. This is reflected in the $P_{2}$ diffusion parameter (median value of $2.74 \cdot 10^{-2} \mathrm{~h}^{-1}$ vs. $1.74 \cdot 10^{-2} \mathrm{~h}^{-1}$ for nanoemulsion and NLC, respectively). Moreover, in this study, the occlusive effect of the NLC component (solid lipid) that usually gives an enhancing effect on skin permeation, did not exceed the effect of thermodynamic activity in the nanoemulsion.

The nanocarrier systems composed of caprylic/capric triglycerides and a biologically compatible surfactant can be considered as good vehicles for forskolin delivery into the skin. According to the obtained results and considering that the developed formulations are for topical application and local purposes, the NLC formulation would provide less forskolin in blood than the nanoemulsion and in this sense it would be more appropriate.

\section{CONCLUSION}

The obtained results showed that not only composition (content of solid lipid, surfactant concentration) but also parameters of homogenization influence the stability of nanostructured lipid carrier formulations (NLCs). The kinetically stable NLCs for forskolin encapsulation containing $4 \%$ of emulsifier (decyl glucoside) were obtained by $\mathrm{HPH}$ process, at $T=75^{\circ} \mathrm{C}, p=275$ bar and 3 pass number of the high-pressure homogenization setting. Moreover, forskolin positively influenced the stability of NLC formulations. The skin permeation results have shown that the obtained NLC formulations could be used as effective carriers for a controlled release of forskolin to the skin, and hence also as an alternative drug carrier in the anticancer drug delivery.

Table 4. Median (and range) of permeation parameters (steady state flux $\left(U_{\mathrm{ss}}\right)$ lag time $\left(T_{\mathrm{L}}\right)$ permeability coefficient $\left(K_{\mathrm{p}}\right) P_{1}$ and $P_{2}$ parameters, and percentage of permeated forskolin at $24 \mathrm{~h}(n=6)$.

\begin{tabular}{lccccc}
\hline Formula & $\begin{array}{c}J_{s 5} \\
\left(\mu \mathrm{g} \cdot \mathrm{cm}^{-2} \cdot \mathrm{h}^{-1}\right)\end{array}$ & $\begin{array}{c}T_{\mathrm{L}} \\
(\mathrm{h})\end{array}$ & $\begin{array}{c}K_{\mathrm{p}} \cdot 10^{3} \\
\left(\mathrm{~cm} \cdot \mathrm{h}^{-1}\right)\end{array}$ & $\begin{array}{c}P_{1} \\
(\mathrm{~cm})\end{array}$ & $\begin{array}{c}P_{2} \cdot 10^{2} \\
\left(\mathrm{~h}^{-1}\right)\end{array}$ \\
\hline IN-emF & $1.96^{*} \pm 0.47$ & $6.66 \pm 3.28$ & $2.82^{*} \pm 0.42$ & $0.119^{*} \pm 0.071$ & $3.29 \pm 2.27$ \\
\hline IIINLCF & $1.77^{*} \pm 0.35$ & $8.68 \pm 2.54$ & $2.37^{*} \pm 0.46$ & $0.124^{*} \pm 0.045$ & $2.18 \pm 1.10$ \\
\hline Labrafac ${ }^{\circ} \mathrm{CC}$ & $6.11 \pm 0.44$ & $6.26 \pm 1.00$ & $8.15 \pm 0.58$ & $0.306 \pm 0.054$ & $2.72 \pm 0.47$ \\
\hline
\end{tabular}

${ }^{*} p<0.05$ with Labrafac CC (Kruskal-Wallis Z-test) 


\section{Acknowledgment of Financial Support}

The research (work) was supported by the European Union through the European Social Fund within "Cracow University of Technology development program - top quality teaching for the prospective Polish engineers; University of the 21 st century" project (contract no.UDA-POKL.04.01.01-00-029/10-00). Financial support from Spanish Ministry of Economy and Competitiveness, MINECO (grant CTQ 2011-29336-CO3-01 and CTQ 2011-29336-CO3-03) is also acknowledged. The authors thank Dr Luís Asmarats from Clínica Sagrada Familia (Barcelona, Spain) for providing skin samples.

\section{REFERENCES}

Burlando B et al (2010) Herbal Principles in Cosmetics: Properties and Mechanisms of Action, pp 212-216. CRS Press Taylor \& Francis Group

Caldero G, Garcia-Celma MJ, Solans C (2011) Formation of polymeric nano-emulsions by a low-energy method and their use for nanoparticle preparation. I Colloid Interface Sci 353: 406-411. doi: 10.1016/j. jcis. 2010.09 .073

Chen H, Chang X, Du D, Liu W, Liu J, Weng T, Yang Y, Xu H, Yang X (2006) Podophyllotoxin-loaded solid lipid nanoparticles for epidermal targeting. J Control Release 110: 296-306. https://doi. org/10.1016/j.jconrel.2005.09.052

Chen Y, Zhu X, Zhang X, Liu B, Huang L (2010) Nanoparticles modified with tumor-targeting $\mathrm{scFv}$ deliver siRNA and miRNA for cancer therapy. Mol Ther 18: 1650-1656. doi: 10.1038/mt.2010.136

Cheng Y, Samia A, Meyers J, Panagopoulos I, Fei B, Burda C (2008) Highly efficient drug delivery with gold nanoparticle vectors for in vivo photodynamic therapy of cancer. I Am Chem Soc 130: 1064310647. doi: 10.1021/ja801631c

De Leeuw J, de Vijlder H C, Bjerring P, Neumann H (2009) Liposomes in dermatology today. I Eur Acad Dermatol Venereol 23: 505516. doi: 10.1111/j.1468-3083.2009.03100

Dhar S, Kolishetti N, Lippard SJ, Farokhzad OC (2011) Targeted delivery of a cisplatin prodrug for safer and more effective prostate cancer therapy in vivo. Proc Natl Acad Sci 108: 1850-1855. doi: $10.1073 /$ pnas.1011379108

Gelfuso G, Cunha-Filho M, Gratieri T (2016) Nanostructured lipid carriers for targeting drug delivery to the epidermal layer. Ther Deliv 7: $735-737$

Gomes, AJ, Lunardi C, Tedesco A (2007) Characterization of biodegradable poly (D,L-lactide-co-glycolide) nanoparticles loaded with bacteriochlorophyll-a for photodynamic therapy. Photomed Laser Surg 25: 428-435. https://doi.org/10.1089/pho.2007.2089

Han F, Li S, Yin R, Liu HZ, Xu L (2008) Effect of surfactant on the formation and characterization of a new type of colloidal drug delivery system: nanostructured lipid carriers. Colloids Surf A 315: 210-216. doi: 10.1016/j.colsurfa.2007.08.005

Jenning V, Schäfer-Korting M, Gohla S (2000) Vitamin A-loaded solid lipid nanoparticles for topical use: drug release properties. I Control Release 66: 115-126. https://doi.org/10.1016/S0168-3659(99)002230

Junyapraserta VB, Teeranachaideekula V, Souto EB, Boonmed P, Müller RH (2009) Q10-loaded NLC versus nanoemulsions: Stability, rheology and in vitro skin permeation. Int J Pharm 377: 207-214. doi: 10.1016/j.ijpharm.2009.05.020

Kemken J, Ziegler A, Muller BW (1991) Investigations into the pharmacodynamics effects of dermally administered microemulsions containing beta-blockers. J Pharm Pharmacol 43: 679-684. https:// doi.org/10.1111/j.2042-7158.1991.tb03457.x

Konan Y N, Gurny R, Allemann E (2002) State of the art in the delivery of photosensitizers for photodynamic therapy. I Photochem Photobiol B 66: 89-106. https://doi.org/10.1016/S1011-1344(01)00267-6
Liu J, Hu W, Chen H, Ni Q, Xu H, Yang X (2007) Isotretinoin-loaded solid lipid nanoparticles with skin targeting for topical delivery. Int J Pharm 328: 191-195. doi: 10.1016/j.ijpharm.2006.08.007

Mulla JS, Khazi IM (2009) Influence of process variables on particle size of solid lipid nanoparticles. Indian I Novel Drug Delivery 1: 47-49

Müller RH, Mehnert W, Lucks JS, Schwarz C, zur Muhlen A, Weyhers H, Freitas C, Ruhl D (1995) Solid lipid nanoparticles (SLN): an alternative colloidal carrier system for controlled drug delivery. Eur J Pharm Biopharm 41: 62-69

Müller RH, Petersen RD, Hommoss A, Pardeike J (2007) Nanostructured lipid carriers (NLC) in cosmetic dermal products. Adv Drug Deliv Rev 59: 522-530. doi: 10.1016/j.addr.2007.04.012

Müller RH, Radtke M, Wissing SA (2002a) Nanostructured lipid matrices for improved microencapsulation of drugs. Int I Pharm 242: 121-128. https://doi.org/10.1016/S0378-5173(02)00180-1

Okamoto, Kamatsu H, Hashida M, Sezaki H (1986) Effects of $\beta$-cyclodextrin and di-o-methyl- $\beta$-cyclodextrin on the percutaneous absorption of butylparaben, indomethacin and sulfanylic acid. Int J Pharm 30: 34-35

Paolino D, Stancampiano AHS, Cilurzo F, Cosco D, Puglisi G, Pignatello R (2011) Nanostructured lipid carriers (NLC) for the topical delivery of lutein. Drug Delivery Lett 1: 32-39. doi: 10.2174/2210304 x11101010032

Pardeike J, Hommos A, Müller RH (2009) Lipid nanoparticles (SLN, NLC) in cosmetic and pharmaceutical dermal products. Int I Pharm 366: 170-184. doi: 10.1016/j.ijpharm.2008.10.003

Passeron T, Namiki T, Passeron H, Le Pape E, Hearing VJ (2009) Forskolin protects keratinocytes from ultraviolet (UV) B-induced apoptosis and increases DNA repair independent of its effects on melanogenesis. I Invest Dermatol 129: 162-166. doi: 10.1038/jid.2008.182

Schwarz C, Menhert W (1999) Solid lipid nanoparticles (SLN) for the controlled drug delivery. II. Drug incorporation and physicochemical characterization. J Microencapsul 16: 205-213. doi: 10.1080/026520499289185

Selzer D, Abdel-Mottaleb MMA, Hahn T, Schaefer UF, Neumann D (2013) Finite and infinite dosing: difficulties in measurements, evaluations and predictions. Adv Drug Deliv Rev 65: 278-294. doi: 10.1016/j.addr.2012.06.010

Souto EB, Müller RH (2005) SLN and NLC for topical delivery of ketoconazole. J Microencapsul 22: 501-510. doi: 10.1080/02652040500162436

Souto EB, Wissing SA, Barbosa CM, Müller RH (2004) Development of a controlled release formulation based on SLN and NLC for topical clotrimazole delivery. Int J Pharm 278: 71-77. doi: 10.1016/j. ijpharm.2004.02.032

Spry ML, Vanover JC, Scott T, et al. (2009) Prolonged treatment of fair-skinned mice with topical forskolin causes persistent tanning and UV protection. Pigment Cell Melanoma Res 22: 219-229

Üner M, Wissing SA, Yener G, Müller RH (2005) Solid lipid nanoparticles (SLN) and nanostructured lipid carriers (NLC) for application of ascorbyl palmitate. Pharmazie 60: 577-582

Vyas A, Kisore Das S, Singh D, Sonker A, Gidwani B, Jain V, Singh M (2012) Recent nanoparticulate approaches of drug delivery for skin cancer. Trends Appl Sci Res 7: 620-635. doi: 10.3923/ tasr.2012.620.635

Williams AC, Cornwell PA, Barry BW (1992) On the non-gaussian distribution of human skin permeability. Int J Pharm 86: 69-77. https://doi.org/10.1016/0378-5173(92)90032-W

Wissing SA, Müller RH (2003) The influence of solid lipid nanoparticles on skin hydration and viscoelasticity - in vivo study. Eur I Pharm Biopharm 56: 67-72. https://doi.org/10.1016/S0939-6411(03)000407

Zheng M, Falkeborg M, Zheng Y, Yang T, Xu X (2013) Formulation and characterization of nanostructured lipid carriers containing a mixed lipids core. Colloids Surf $A$ 430: 76-84. https://doi. org/10.1016/j.colsurfa.2013.03.070 